\title{
DIGITALIZAÇÃO DA CONSTRUÇÃO EM PORTUGAL: A NOVA SEDE DA PHC NO TAGUSPARK
}

\author{
Filipe Lima $^{(1)}$, Sébastien Roux ${ }^{(1)}$, João Marcelo ${ }^{(2)}$ Alexandra Calheiros ${ }^{(2)}$ \\ (1) Limsen Consulting, Lisboa \\ (2) DST, Braga
}

\begin{abstract}
Resumo
No contexto crescente de digitalização da construção em Portugal, o projecto e construção em curso da nova sede da PHC, no Taguspark, são um caso de estudo relevante da aplicação de metodologias BIM durante o ciclo de vida dum edifício, assim como um exemplo da natureza "Bottom-Up" que a implementação do BIM está a tomar em Portugal. Por "Bottom-Up" entende-se uma implementação de baixo para cima, ou seja, neste caso, da indústria para os Donos de Obra. A utilização do BIM nasceu neste projecto dum acordo inicial entre os projectistas e gestores de projecto de levar o BIM até à obra, com adesão posterior do dono de obra (DO) e empreiteiro. Todos os projectistas e consultores trabalharam em BIM ao longo do projecto e acompanhamento da obra e trocaram modelos através de um Common Data Environment (CDE), com escasso recurso a peças desenhadas 2D. Ao longo da fase de projecto, aconteceram igualmente vários processos de implementação BIM em vários intervenientes deste processo, desde a gestão de obra, às empresas de especialidades e medições. O papel do gestor BIM foi essencial no acompanhamento de todas estas empresas, assim como a escolha duma construtora já familiarizada com execução de obras em BIM para levar o esforço conjunto de todos para o estaleiro. A génese do próprio contrato de empreitada “Open-book" foi propício ao desenvolvimento das metodologias BIM e vice-versa. Uma vez que o orçamento delimitado pelo DO teria de ser cumprido por todos, os modelos digitais e a sua quantificação permitiram um constante ajuste dos orçamentos para cumprir as metas que foram fixadas. Pretende-se apresentar de seguida este caso de estudo.
\end{abstract}

\section{Introdução}

Os últimos dados divulgados pelo Fórum Económico Mundial revelam que a adopção do BIM varia na razão do nível de desenvolvimento económico de cada país [1], o que deixa Portugal, economia de escassa liquidez, com pouca capacidade para investir nas vantagens da construção digital. Por oposição, verifica-se que os países mais prósperos são capazes de definir uma visão para a transformação digital, o que à partida conduz a uma resposta da indústria mais homogénea. $\mathrm{O}$ fenómeno descrito significa, para o caso nacional, que a ausência da decisão de 
nível macro abre espaço, muitas vezes, a iniciativas individualizadas de pequenos actores da indústria, sendo estes responsáveis, de modo orgânico, por processos de disseminação BIM. Como consequência directa, verifica-se um baixo nível de uniformização da informação digital dos empreendimentos da construção [2], o que claramente compromete a fluidez da transmissão de dados entre todos os intervenientes. Contudo, estas acções apresentam uma segunda ramificação, positiva, que consiste na capacidade de demonstrar resultados práticos e mensuráveis, no terreno, da aplicação de metodologias digitais. Perante esses resultados, as entidades contratantes e outras instituições ganham confiança e aceleram a própria implementação BIM nos seus processos.

Pretende-se de seguida apresentar um caso exemplificativo deste tipo de interação.

\begin{tabular}{ll}
\hline Intervenientes & Área de Intervenção \\
\hline TAGUSPARK & Dono de Obra (DO) \\
ALPHALINK & Gestora de Projecto \\
OPENBOOK & Projectista de Arquitectura \\
JLCM & Projectista de Estruturas \\
GRAUCELSIUS & Projectista de Redes e Serviços (AVAC, Águas e Esgotos e \\
TRIBATO & Segurança contra Incêndios) \\
DST & Medidor Orçamentista (Arquitectura) \\
LIMSEN & Construtora \\
\hline
\end{tabular}

As empresas citadas acima foram essenciais para fazer acontecer esta empreitada em BIM.

\section{O BIM durante a fase de projecto}

\subsection{O projectista de arquitectura na génese do processo}

O projectista de arquitectura aderiu ao BIM desde a sua constituição como empresa de projecto em 2007. Esta decisão estratégica começou com a simples escolha do software de produção que iriam adoptar, neste caso o Revit. Durante os anos de crise, a equipa encolheu e voltou a aumentar, o que levou a um crescimento desordenado a níveis variáveis de domínio das ferramentas dentro da empresa. Em 2018, foi entregue à consultora BIM a tarefa de unificar os processos de trabalho BIM, implementação essa que teve a previsão inicial de um ano. $\mathrm{O}$ projectista de arquitectura é provavelmente um caso raro a nível nacional e talvez até internacional, já que se trata duma empresa que nunca trabalhou em CAD e sempre desenvolveu todos os seus projectos em Revit. O termo implementação, neste caso, será visto na perpespectiva dos processos, e não do software, cujo domínio operativo era já uma realidade. Em 2018, no início da implementação, o projectista de arquitectura estava isolado no seu ambiente BIM, sem consultores que acompanhassem o seu esforço. A modelação era um dos fortes da empresa, assim como a realidade virtual, na qual tinha havido uma forte aposta. A gestão de informação era o ponto fraco dos modelos. Na estratégia delineada, definiram-se então dois pontos essenciais: 
1. Melhorar a Informação e coerência dos modelos para medir integralmente a partir do BIM

2. Trazer os projectistas de especialidades a bordo e melhorar a colaboração

Ao longo de 2018 foi atingido, um nível de maturidade suficiente ao longo de vários projectos piloto que lançaram as bases para o projecto agora apresentado.

\subsection{A fase conceptual}

O potencial do uso do BIM em fases conceptuais é raramente referido [3], no entanto, há muito em jogo nesta fase e o BIM é uma ferramenta essencial na análise de opções de projecto. Em particular, a vertente da realidade virtual aproxima o DO da conceptualização do projecto, permitindo-lhe uma leitura mais directa dos estudos realizados. O uso do Revit, como ferramenta de modelação, em conjunto com o Enscape, como ferramenta de realidade virtual, foram muito importantes para a continuação de todo o processo, permitindo um entendimento das opções de projecto por parte do DO. Ainda durante esta fase, o projectista de arquitectura, no seguimento do seu processo de implementação BIM, desafiou os restantes intervenientes a desenvolver o projecto em BIM. Tanto o projectista de estruturas, como o projectista de redes e serviços iniciaram-se no BIM com este projecto piloto. A gestora de projecto foi igualmente importante neste processo tendo adaptado os seus procedimentos aos novos processos digitais: até agora habituados a fiscalizar os projectos em 2D, adaptaram-se ao uso duma CDE e à monitorização de projecto através da visualização de modelos, tendo, finalmente, integrado o BIM nas exigências de contratação de empreiteiro. Mais tarde, o medidor orçamentista para a arquitectura, empresa especializada em medições com mais de 20 anos de experiência em processos baseados em CAD, adaptou igualmente o seu método de trabalho a esta metodologia, medindo o projecto a partir do modelo de arquitectura com recurso ao Navisworks. A montante desse trabalho, no entanto, os procedimentos de modelação específicos para que as quantidades possam ser geridas de modo consistente exigem preparação. Esta componente fez parte do processo de implementação que a consultora BIM vinha a desenvolver junto do projectista de arquitectura, o que permitiu ter um controlo da informação do modelo muito robusto.

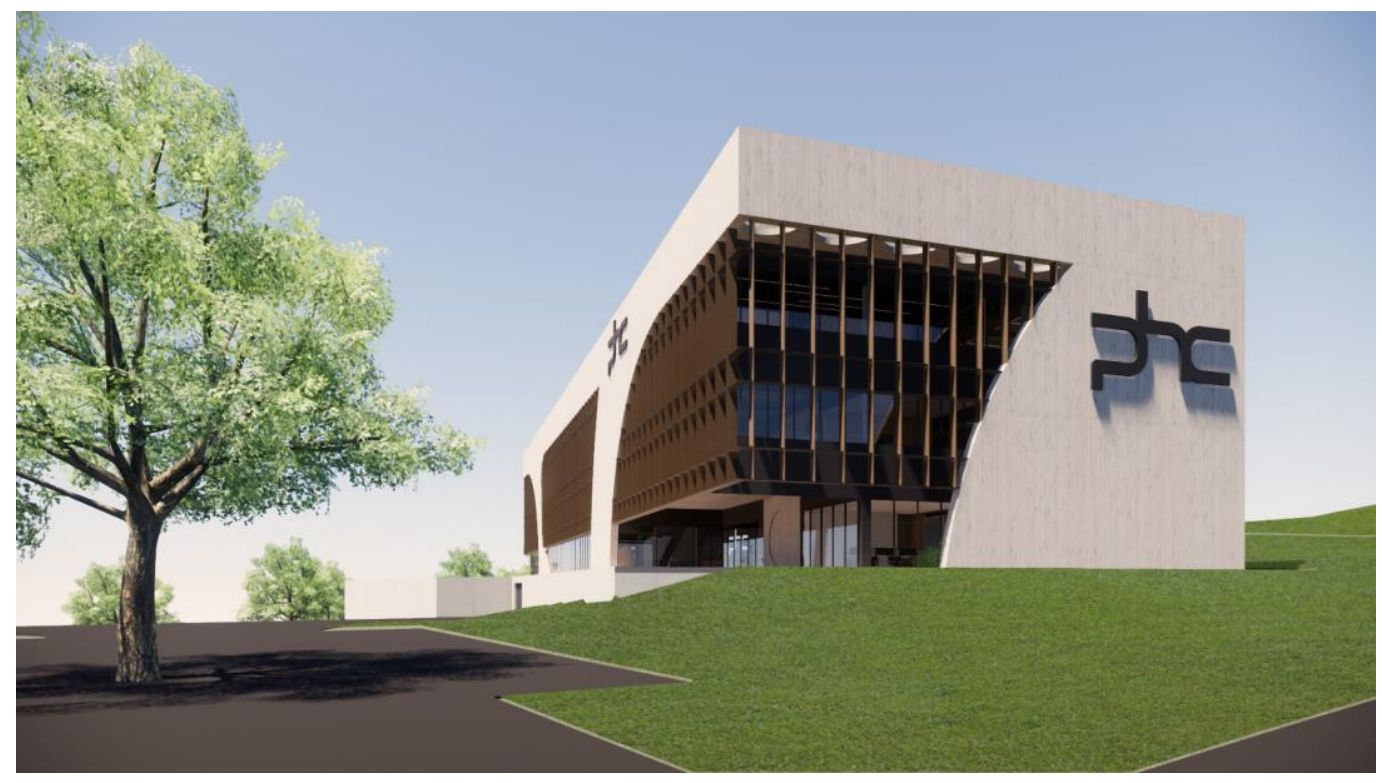

Figura 1: Render durante o Estudo Prévio - Revit + Enscape. 


\subsection{O Projecto de Execução}

A colaboração entre equipas de projecto começou, verdadeiramente, nesta fase. Já com todos os consultores a bordo, coube à consultora BIM desenvolver um plano de execução BIM (PEB) e acompanhar as equipas ao longo das suas dificuldades. O PEB, atendendo a que foi estabelecido já a meio do processo, teve de ser o mais pragmático possível com definições de LOD até ao nível 300 e 3 usos BIM prinicipais:

1 - Produção de desenhos a partir dos modelos

2 - Coordenação

3 - Controlo de quantidades e custos

Foi também escolhido o A360 como CDE, tratando-se na altura duma ferramenta acessível com uma boa visualização de modelos federados, troca de informação e comentários, e uma gestão documental razoável. Foi também instaurado um protocolo de troca de informação semanal com vários níveis de validação conforme descritos na ISO 19650 [4]:

1 - WIP para modelos de trabalho

2 - SHARED para troca de informação fiável

3 - PUBLISHED para informação validada pelo DO

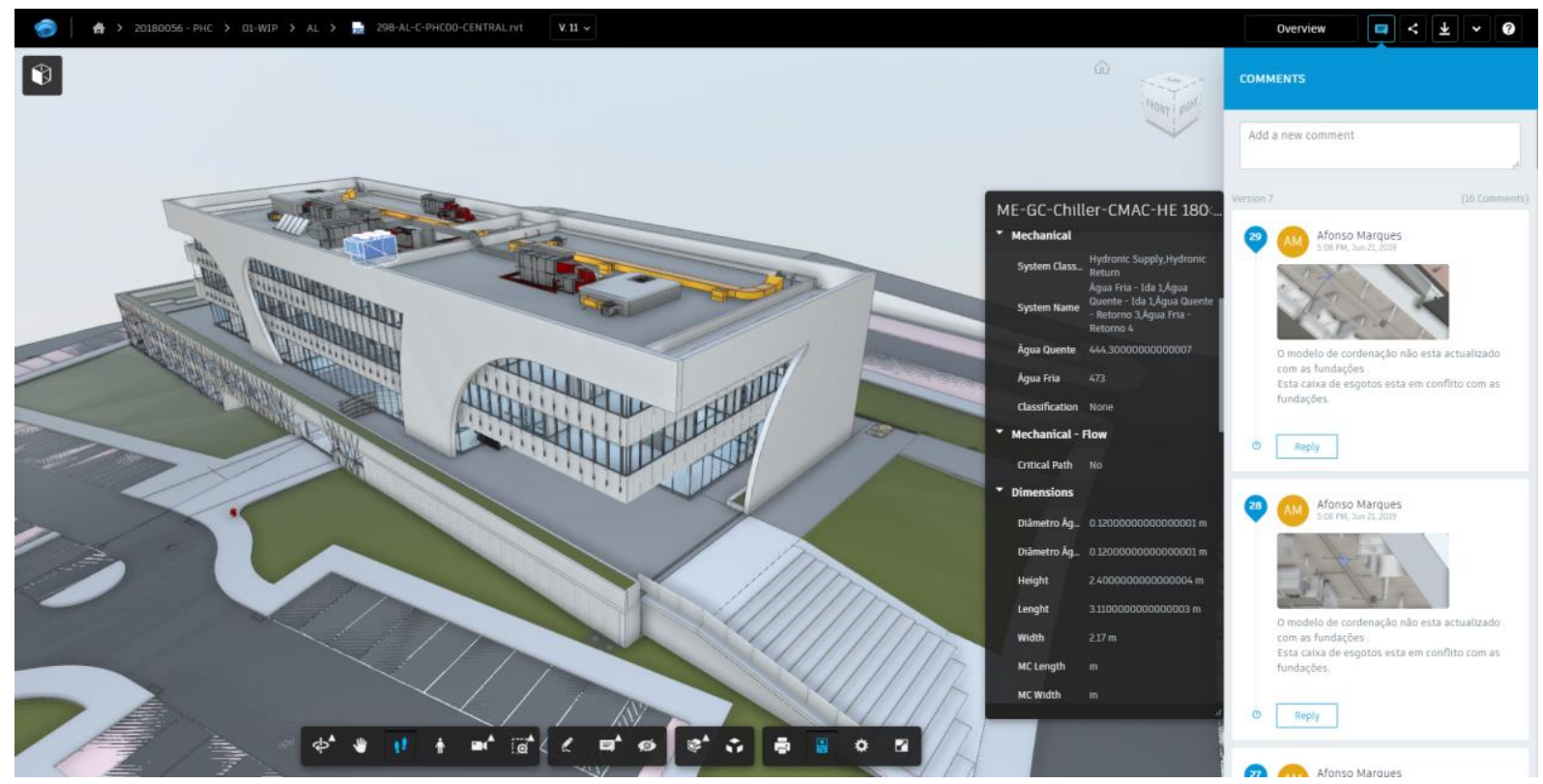

Figura 2: CDE - Visualização das propriedades dum equipamento mecânico no A360 e comentários.

Todos os projectistas, com a excepção das estruturas, modelaram em Revit. Os formatos autorizados foram o .rvt e ifc para troca de informação com as especialidades que modelaram no Pro Structures da Bentley. Um dos principais desafios neste caso prendeu-se com os diferentes sistemas de coordenadas. 


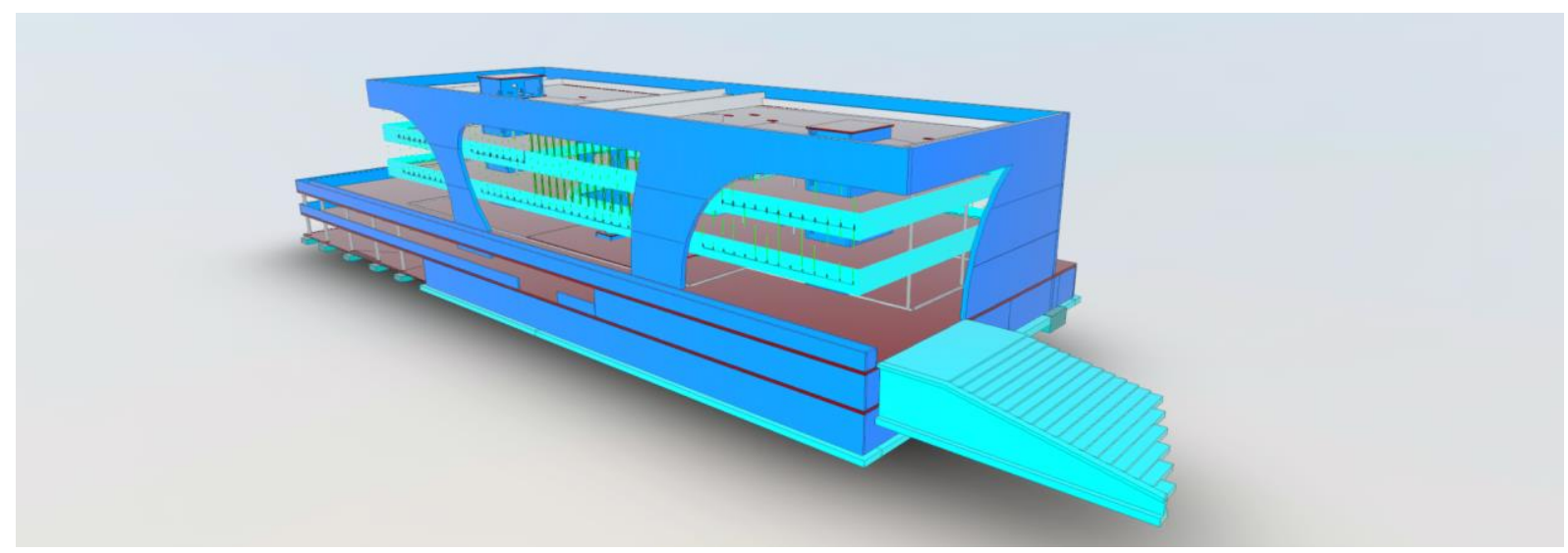

Figura 3: Modelo .ifc da Estabilidade.

Nas reuniões de coordenação de projecto recorreu-se principalmente ao Enscape e ao A360. O Enscape, para além da sua vertente de renderização, é uma ferramenta de realidade virtual muito eficiente que permite visitar os projectos com um grande nível de imersão, o que permitiu detectar muitos erros de projecto numa fase inicial, assim como validar opções de AVAC, sprinklers e SCI com grande impacto visual no projecto. O A360, para além da visualização do modelo e consulta da informação disponível, permitia igualmente a visualização das peças desenhadas e anotação das mesmas para revisão.

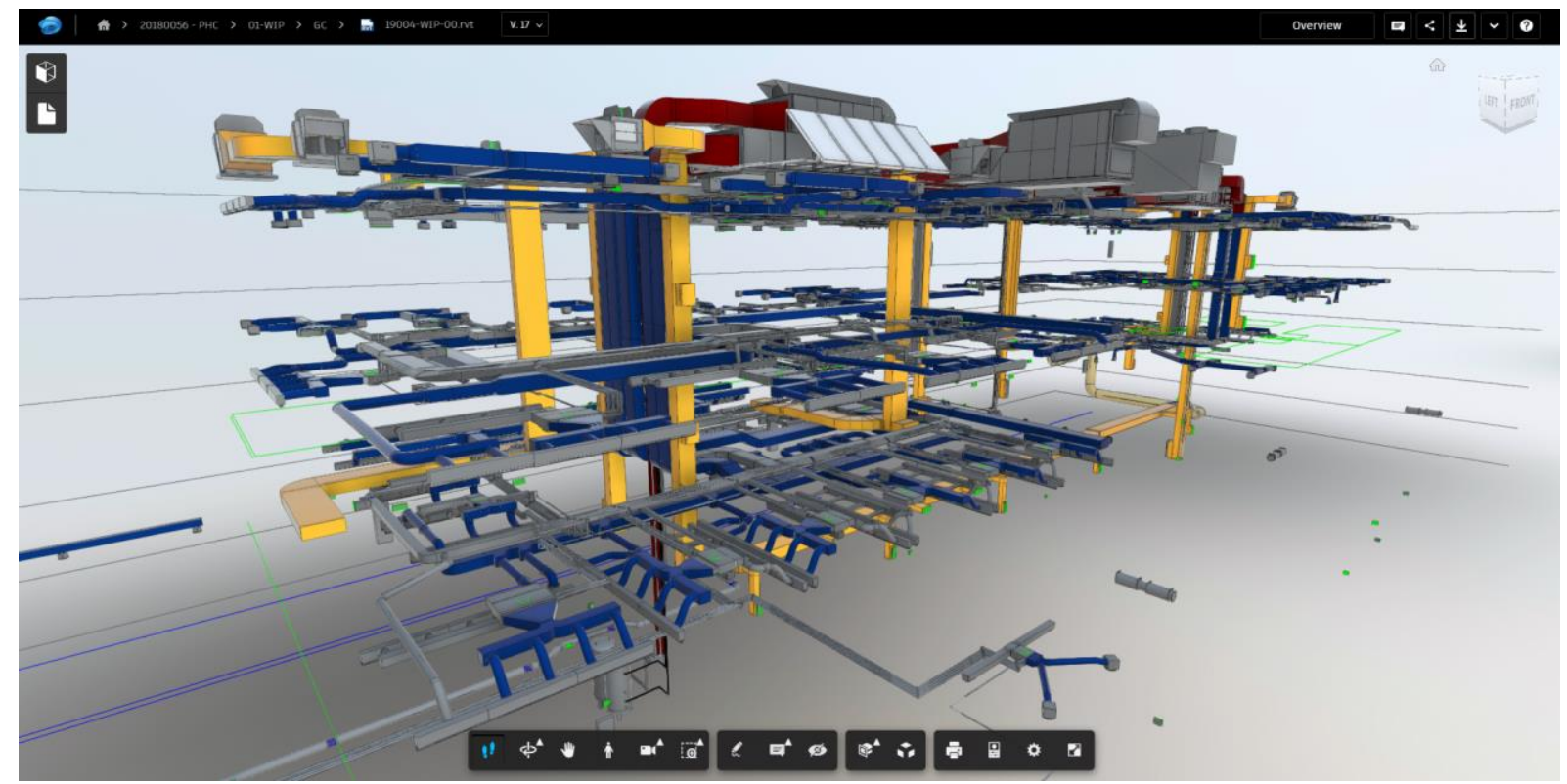

Figura 4: Modelo do AVAC.

\subsection{Coordenação e consulta de empreitada}

No final do Projecto de Execução, é comum fazer a compatibilização dos modelos federados, também conhecida por Clash Detection, e respectiva revisão dos projectos por parte dos projectistas. A construtora selecionada para a empreitada já estava familiarizada com processos BIM e também procedeu aos mesmos testes de colisões. Ao mesmo tempo, realizou 
verificações das quantidades sobre os modelos, sendo o processo facilitado por todos os projectos terem sido desenvolvidos integralmente em BIM, com a única excepção das redes eléctricas. Durante o processo de transição do projecto para a obra, ficou acordado com a construtora que os modelos de especialidades passariam a ser propriedade da mesma, com o aval dos respectivos projectistas, e que a arquitectura se manteria do lado do projectista original. Deste modo, a responsabilidade da gestão e edição de cada modelo para efeito de adaptações/optimizações em obra, assim como para a emissão das telas finais ficou estabelecida.

\section{BIM em obra}

$\mathrm{O}$ arranque da execução de obra marca o momento em que as ferramentas BIM atingem a totalidade da cadeia construtiva, ou seja, os modelos BIM permitem um envolvimento das equipas de produção, subempreiteiros, encarregados, preparadores, topografia e os trabalhadores que irão executar todas as especialidades da obra, com a toda a equipa que até este momento esteve envolvida no processo de projecto. Em consequência, um atributo extremamente vantajoso é a diminuição da distância que normalmente ocorre entre DO e projetistas, com as equipas de execução, possibilitando deste modo que as tomadas de decisão ocorram de uma forma mais célere, apoiadas num grau superior de certeza [5].
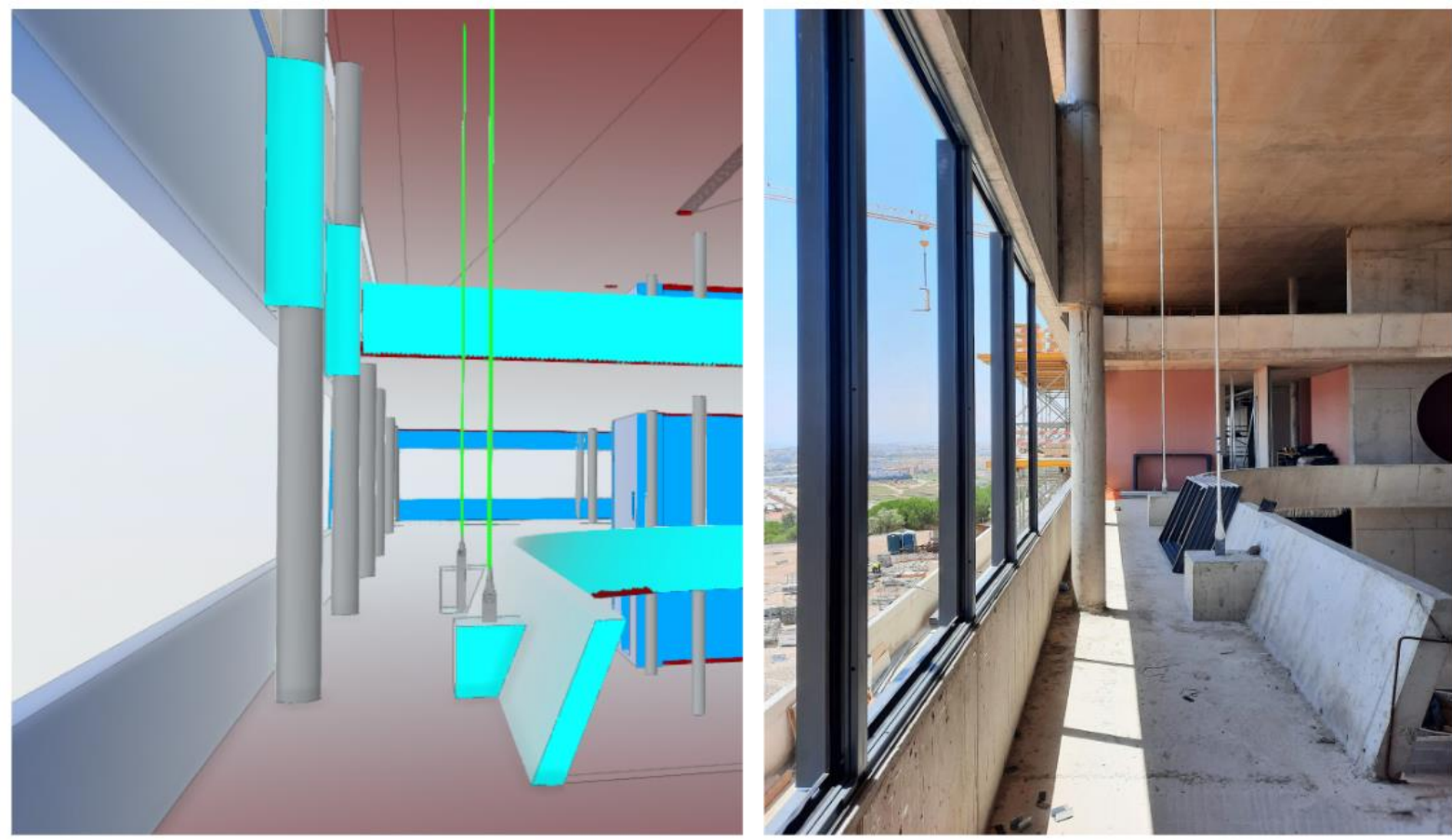

Figura 5: Comparativo entre modelo de estruturas e betão executado em obra.

Após a seleção da construtora e arranque dos trabalhos de execução de obra, percebeu-se, em termos do enquadramento económico da obra, ser necessário proceder a uma otimização orçamental. Para este efeito realizaram-se as seguintes ações: 
1. A construtora convocou um subempreiteiro interno de forma a otimizar o projeto nas vertentes de AVAC e Eletricidade. Nesta fase em que se pretende otimização orçamental, o envolvimento de uma empresa de execução com capacidades de projeto torna-se essencial para num espaço de tempo diminuto analisar-se o impacto financeiro das soluções a propor;

2. O projectista de arquitectura articulou os trabalhos de otimização da arquitetura e, por sua vez, a gestora de projecto assegurou a compatibilização das especialidades de estruturas e redes hidráulicas;

3. A equipa BIM da construtora, tendo como base os modelos remetidos em fase de concurso, apoiou o subempreiteiro no sentido de que os projetos de AVAC e Eletricidade fossem realizados em BIM;

4. Para além da realização dos modelos de AVAC e Eletricidade, a equipa BIM da construtora articulou a troca de informação entre gestora de projecto, projectistas, orçamentação e direção de obra da própria construtora, com o intuito de garantir que através das ferramentas BIM, modelos, desenhos e mapas de quantidades, as soluções a propor serão analisadas por todos;

5. De forma a materializar os pontos supra, foram promovidas reuniões semanais entre todos os intervenientes, em que os modelos BIM foram a base das reuniões, sendo o apoio necessário para apresentação, validação ou alteração das soluções que configuração o processo de otimização;

6. Em termos de modelos, procedeu-se a um envio semanal de modelos editáveis e não editáveis, de forma a que todos os intervenientes pudessem trabalhar sobre os modelos mais atualizados das restantes especialidades;

7. Salienta-se que a gestora da projecto, relativamente aos projetos de Eletricidade e AVAC, procedeu à sua validação por intermédio de consultoras externas, que analisaram a informação através das ferramentas proporcionadas pelo BIM;

8. No que concerne ao modelo de estrutura, após otimização, a responsabilidade do modelo passou para a alçada da equipa BIM da construtora, no sentido de se analisar as aberturas a realizar tendo por base a análise das restantes especialidades. Importa salientar que as aberturas propostas foram sempre colocadas à consideração da equipa de projeto, tendo ocorrido sucessivos processos de iterações entre as equipas de arquitetura, estruturas e especialidades, de forma a validar a informação a tempo útil da frente de obra;

9. No decurso do processo de otimização do projeto, a obra iniciou os trabalhos, sendo necessário, por parte da equipa de gestão de projecto e equipa BIM da construtora, um trabalho de perceção dos pontos críticos para o desenvolvimento da obra de forma a proceder às validações e aplicação da informação na frente de obra;

10. Após validação das soluções propostas no processo de otimização, a equipa BIM da construtora procedeu à elevação do nível dos modelos de modo a torná-los próximos da geometria de execução. Nesta fase, a construção reúne-se com os chefes de equipa dos subempreiteiros e, em conjunto, analisa-se a componente de peças e geométrica do modelo de modo a ganhar a confiança das equipas instaladoras.

Na Tabela 1 pode visualizar-se a matriz de responsabilidade dos modelos BIM, por especialidades, para cada fase da obra. 
Tabela 1: Matriz de Responsabilidade dos Modelos BIM em cada Fase do Processo

\begin{tabular}{llll}
\hline Especialidade & Projeto & Otimização Orçamental & Execução de Obra \\
\hline Arquitetura & Projectista & Projectista & Projectista \\
Estruturas & Projectista & Gestora de Projecto & Equipa BIM da construtora \\
Eletricidade & Projectista & Equipa BIM da construtora & Equipa BIM da construtora \\
Redes Hidráulicas & Projectista & Gestora de Projecto & Equipa BIM da construtora \\
AVAC & Projectista & Equipa BIM da construtora & Equipa BIM da construtora \\
\hline
\end{tabular}

Importa salientar que a passagem de informação para a frente de obra se processa através de peças desenhadas, sendo estas subdividas por zonas e por especialidades. Para além do apoio através dos modelos disponíveis em obra e das peças desenhadas, para as especialidades de eletricidade e de AVAC procedeu-se à marcação em obra a partir dos modelos digitais. $\mathrm{Na}$ prática, o investimento no rigor desenvolvido na fase de projecto foi transposto directamente para a obra, através de HDS (high definition scanning), reduzindo deste modo a intervenção humana e o erro que lhe é associado [6]. Para se atingir o objetivo descrito, foram desenvolvidas as seguintes etapas:

1. Desenvolvimento de plug-ins para os softwares de modelação com o intuito de indicação automático para os equipamentos de marcação dos pontos que se pretende marcar in situ, Figura 6;

2. Para a marcação in situ utilizou-se uma estação total "clássica", Geomax Zoom 90, controlada através da controladora Getac ZX70 com software Xpad, ao qual foi adicionado software que permite a leitura e a escrita em modelos bim;

3. Procedimento de georreferenciação da estação total num determinado espaço da obra e os modelos BIM, visíveis na controladora, através de elementos já executados, evitando deste modo apoio topográfico;

4. Gravação manual nos elementos estruturais executados da marcação projetada pela estação total.

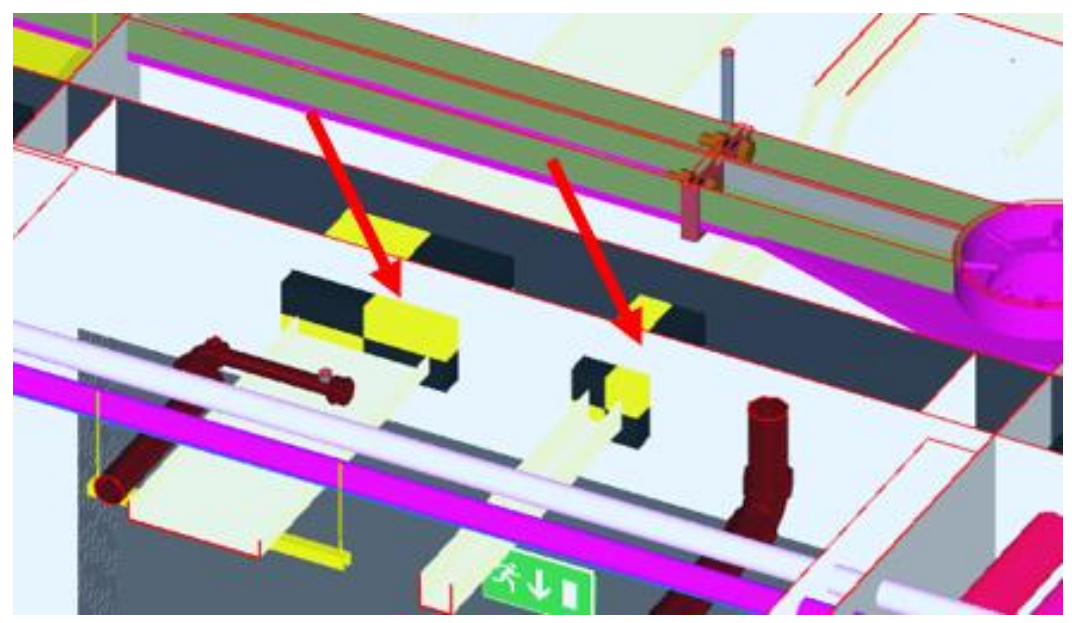

Figura 6: Marcação dos negativos no Modelo. 


\section{Conclusão}

A cooperação e coordenação entre empresas envolvidas no ciclo de vida do ambiente construído permanece uma lacuna evidente na sua capacidade de gerar valor [7]. Para lá dos desafios que a sua implementação apresenta, a digitalização da indústria da AEC oferece uma oportunidade real de aumentar a eficiência dos processos de projecto/obra/operação. Isto é sobretudo válido pela maior clareza que o modelo digital de informação traz à comunicação. Todavia, as soluções tecnológicas não determinam, por si, uma melhoria na cadeia de produção, sobretudo quando esta trabalha de um modo desintegrado [1]. A dimensão dos recursos humanos, dos processos e das organizações desempenha, então, um papel determinante na capacidade de gerar ganhos de produtividade [8]. Nesse sentido, um contexto em que os processos digitais estejam uniformizados e os requisitos de informação identificados, em cada projecto, numa fase inicial, parece aumentar a probabilidade de sucesso dos processos construtivos. No entanto, é curioso verificar que o projecto em análise, não beneficiando dessas condições e tendo progredido de um modo orgânico, permitiu obter resultados consistentes e com proveitos para os vários intervenientes.

Em concreto, a fase de projecto acomodou duas dimensões que ocorreram em simultâneo: o desenvolvimento dos próprios projectos e o processo de implementação BIM nalgumas das empresas envolvidas. Isto gerou um processo colaborativo mais claro e informado, do qual o DO fez parte, e permitiu às empresas um incremento nas suas capacidades digitais, o que será estratégico no longo prazo [9]. No caso dos modelos desenvolvidos pela arquitectura, foi possível ultrapassar as limitações que a modelação feita para emitir desenhos tem, por vezes, com a modelação feita para extrair quantidades [10]. Ou seja, o mesmo modelo permitiu estes dois usos sem que o segundo comprometesse a qualidade do primeiro.

$\mathrm{Na}$ fase de obra, face às ações desencadeadas e comparativamente com um procedimento de otimização de projeto clássico, verificou-se que a utilização de modelos BIM permite que o processo de optimização ocorra em simultâneo com a execução da obra, isto porque o modelo constitui uma base de confiança para as equipas que se encontra in situ a executar a obra. Outro aspecto evidente foi o encurtamento de tempo de tomadas de decisão, factor crítico enquanto decorre a empreitada.

Finalmente, regista-se o facto de que o DO, não tendo estado na origem da utilização do BIM neste processo, ao compreender a possibilidade das mais-valias envolvidas, equaciona actualmente a utilização do modelo digital "As-Built" para informar a plataforma de gestão de activos durante a operação do edifício. Esta sequência de eventos configura uma dinâmica de adopção de competências digitais do tipo "Bottom-Up", em que intervenientes de menor escala na área do projecto, em conjunto com construtoras, difundem o BIM de forma vertical até às instituições contratantes, passando estas a integrá-lo formalmente [11].

\section{Referências}

[1] W. E. Forum, "An Action Plan to Accelerate Building Information," 2018.

[2] L. Campos and A. Aguiar Costa, "CONCEITOS PARA A UTILIZAÇÃO DE INFORMAÇÃO DIGITALIZADA NO CICLO DE VIDA DE EMPREENDIMENTOS DE CONSTRUÇÃO,” $2^{\circ}$ Congresso Português de Building Information Modelling, 2018. 
[3] A. Kereshmeh, "Building Information Modeling in Concept Design Stage," University of Salford, Manchester, 2012.

[4] E. C. F. STANDARDIZATION, "EN ISO 19650-1; "Organization and digitization of information about buildings and civil engineering works, including building information modelling (BIM) Information management using building information modelling".

[5] D. Hammad, A. Rishi and M. Yahaya, "MITIGATING CONSTRUCTION PROJECT RISK USING BUILDING INFORMATION MODELLING (BIM)," Building Technology Programme, Department of Technical Education, College of Education Azare Bauchi State, Nigeria, 2012.

[6] Group, Boston Consulting, "The Transformative Power of Building Information Modeling," 2016.

[7] W. E. Forum, "Shaping the Future of Construction - A Breakthrough in Mindset and Technology," 2016.

[8] Surveyors, Royal Institution of Chartered, "Building Information Modelling for Project Managers," 2017.

[9] Group, Boston Consulting, "The Digital Imperative," 2015.

[10] A. Monteiro and J. Poças Martins, "A survey on modeling guidelines for quantity takeoff-oriented BIM-based design,” 2013.

[11] M. Kassem and B. Succar, "Macro BIM adoption: Comparative market analysis," 2017. 